\title{
Optimal management of power networks using a dynamic line rating approach
}

\author{
J. Duque ${ }^{1}$, D. Santos ${ }^{1}$, A. Couto ${ }^{1}$ and A. Estanqueiro ${ }^{1}$ \\ ${ }^{1}$ Renewable Energy and System Integration Unit \\ Laboratório Nacional de Energia e Geologia, I.P. (LNEG) \\ Estrada do Paço do Lumiar, 22, 1649-038 Lisboa (Portugal) \\ Phone number: +351 210924 600, e-mail: joaquim.duque@lneg.pt, ana.estanqueiro@lneg.pt
}

\begin{abstract}
Due to the stochastic nature of wind, the wind power integration into the power system poses serious challenges to the transmission system operators (TSO). The impact of large amounts of wind energy generation onto the power system may congest some of the transmission lines that transport it to the (sometimes) distant consumption centres. Since the occurrence of wind not only contributes to the loading of the connecting electric line, but also increases the line capacity, via convective cooling of the cables, a dynamic line rating (DLR) analysis computes a more realistic set of values for the line capacity, thus it can be a cost-effective solution to alleviate some overhead line congestion problems.

This work presents an operational tool for the DLR analysis of power networks, allowing the optimal integration of renewable energy sources, especially where potentially congested lines may exist. The tool was applied to a real case study using forecast meteorological data, and the results achieved were compared with those obtained by using the Portuguese TSO method for assessing the transmission capacity of the lines. For high wind speed conditions, results show a noticeable increase on the cable's convective cooling assessed by the DLR analysis. This assessment leads to a noticeable rise on the cables' capacities that overcame the congestion associated with the high injection levels of wind power generation in the power grid.
\end{abstract}

\section{Key words}

Wind power integration, DLR, Cable thermal balance, Optimal power flow, Overhead power lines.

\section{1) Introduction}

The distributed nature of the ever increasing renewable energy sources (RES), along with the need to bring that energy to the usually distant consumption centres (cities and industrial parks), raises new problems to the transmission power systems operators (TSOs) [1]. In fact, the high penetration of RES production, as is the case for Portugal, can overload the overhead electric power lines (OHLs) of the existing transport/distribution power grid an adverse occurrence traditionally solved by upgrading the existing power lines, building new power lines or by limiting RES production, which have several negatives impacts (both economic and ecological). One factor limiting the RES capacity that can be injected into the grid is, usually, the maximum ampacity of the overhead lines imposed by the line temperature limit [2]. This limit is established to ensure the: i) safety distance between the lines and the ground, and the ii) structural integrity of the cables [3].

Nowadays, in several countries such as Portugal, the TSOs use numerical models to assess the cables "SteadyState" thermal equilibrium for a predetermined set of local extreme meteorological conditions, which defines the maximum ampacity of the overhead power lines. In the steady state model, the electrical current, conductor temperature, and weather conditions are assumed constant [3]. In recent years a set of measured or forecasted meteorological conditions have been used instead to obtain more realistic values for cable's ampacity[3]-[5]. By including the cables thermal inertia a more general thermal analysis approach is obtained leading to the dynamical thermal balance, where the conductor's temperature varies in time. These considerations lead to complex numerical thermal models such as the IEEE Std 738 - 2012 [3], CIGRÉ [4] and Kuipers\&Brown [5] approaches, under development for the last three decades. Despite that, the focus from the TSOs in the dynamical thermal balance analysis as operational tool is recent, since the probability of overloading the power lines was considerably reduced before the steep rising of wind power production [4]. Such models use algorithms to dynamically assess the thermal gains and losses on the cables, from a set of thermal effects imposed by local meteorological conditions. Thus, according to [1], [2], [6], the benefits from implementing a DLR to assess the conductor thermal behaviour are: grid's reinforcement postponement, RES penetration increase, cost minimization of power reserves and electricity prices (by RES curtailment mitigation).

Conductor temperature can vary significantly along its length due to the meteorological conditions, especially in 
complex orographic regions [7]. In fact, the DLR analysis using local meteorological conditions may increase the line capacity by $10-30 \%$ [8]. According to the authors, the additional capacity occurring from installing real time meteorological data monitoring represents a cost reduction of up to $2 \%$ less than the cost to achieve an equivalent gain by line upgrading [8]. A study conducted in the north-west of Germany, using the IEEE model and historical meteorological data, shows that the line capacity can increase more than $125 \%$ during $50 \%$ of the time [6]. On the other hand, the authors account only $5 \%$ of the time for capacity values lower than the ones used by the local TSO. This study highlighted the strong correlation (0.72) between the injected wind power generation and the increase in the line's capacity. Regarding the meteorological data, the wind speed is described by several authors as the parameter having the greatest impact in the conductor thermal balance, followed by wind direction and ambient temperature, while the effect of solar radiation is much reduced when compared with the previous parameters [9]. Since the primary resource that feeds the wind parks - wind - also blows over the local power lines, besides the energy production it also increases the lines' ampacity. Consequently, the wind cooling effect provides additional power line capacity when it is most needed, leading to a win-win situation [9]. Thus, operational DLR analysis tools may be and are already used in some specific cases [2] to cope with high levels of wind power penetration in the power grid, avoiding potential line congestion. Moreover, the DLR analysis can also be used as a planning tool to determine the line segments that can benefit from temperature monitoring [7]. This work presents an operational tool for the DLR analysis of potentially congested electrical networks, based on CIGRÉ methodology, to cost-effectively optimize the integration of RES in the existing power grids. A GIS suite (ArcGIS) is used as a tool's interface to input, process and present the data. A real case study in Portugal is used to assess the grid power line's capacities obtained with the DLR analysis for diverse meteorological local conditions. As a baseline, the results are compared with the current "Steady-State" analysis used by the Portuguese TSO.

Section 2 provides a brief description of the data and methodology. Section 3 presents the results obtained. In section 4 , some final remarks are provided.

\section{2) Data and Methodology}

\section{A. Data}

The case study used to illustrate the operation of the DLR analysis tool corresponds to an area located in the interior central part of Portugal, Fig. 1. The high wind potential in this area and its orography favours the exploitation of RES, namely, wind and hydroelectric energy. 45 wind parks with a total installed capacity of $1480 \mathrm{MW}$ and 14 large hydroelectric power stations totalling $1060 \mathrm{MW}$ are deployed in this region. Consequently, by choosing this region, it is possible to 1) study the network behaviour under considerable high variable power injection levels, 2) determine the power injection from wind parks taking into considerations the expected power output under the imposed weather conditions and 3) assess the simultaneous effect of the cooling effect induced by the wind resource in the overhead lines and its impact on the capacity factor.

In this study, the power grid is composed of different types of electric cables, with different physical properties[10]-[12]. Table I presents the conductors' characteristics used by the model.

Table I. Line cable conductors physical properties.
\begin{tabular}{|c|c|c|c|c|c|}
\hline Name & $\begin{array}{c}\text { Resistivity } \\
{[\mathrm{ohm} / \mathrm{km}]}\end{array}$ & $\begin{array}{c}\text { Overall } \\
\text { diameter } \\
{[\mathrm{mm}]}\end{array}$ & $\begin{array}{c}\text { Wires } \\
\text { diameter } \\
{[\mathrm{mm}]}\end{array}$ & $\begin{array}{c}\text { Emissivity } \\
{[\text { Adim. }]}\end{array}$ & $\begin{array}{c}\text { Maximal } \\
\text { temperature } \\
{\left[{ }^{\circ} \mathrm{C}\right]}\end{array}$ \\
\hline Zebra & 0.0674 & 28.6 & 3.18 & 0.6 & $50,75,85$ \\
\hline Bear & 0.1093 & 23.45 & 3.35 & 0.6 & 50 \\
\hline $\begin{array}{c}\text { Aster } \\
570\end{array}$ & 0.0583 & 31.05 & 3.45 & 0.6 & 80 \\
\hline
\end{tabular}

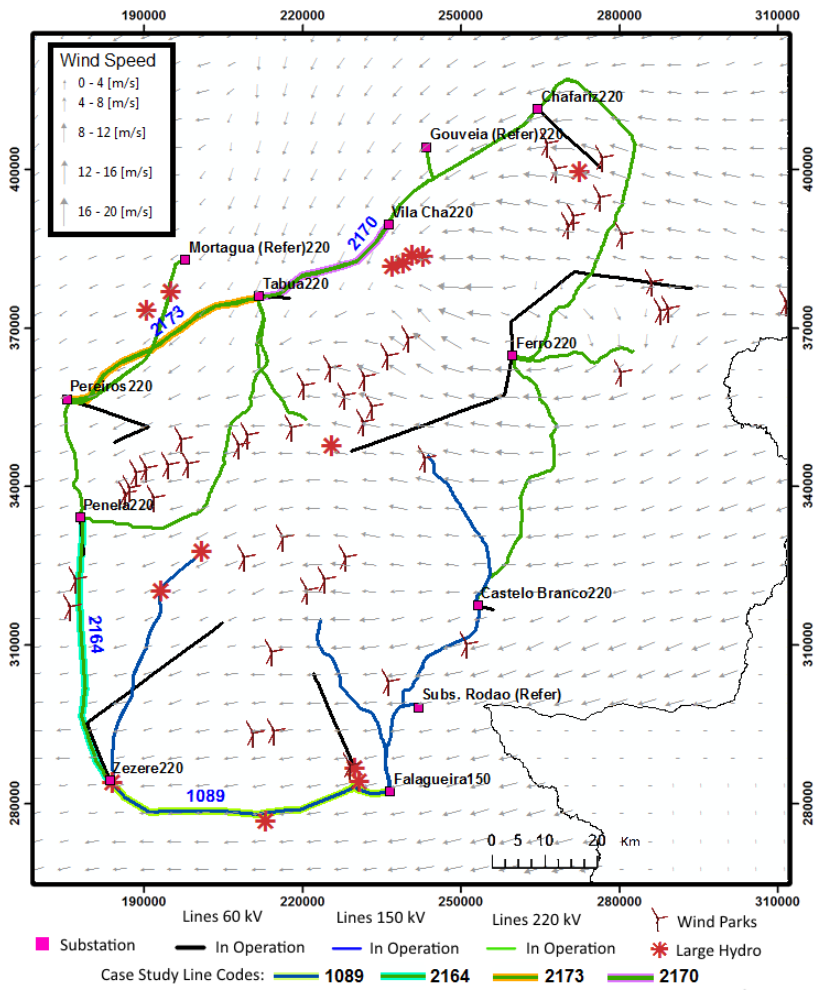

Fig. 1 Case study's electric grid of Pinhal Interior (wind speed and direction at December 23, 2009 at 1:00 p.m.). The potentially congested lines are identified by its line code.

The hourly meteorological data for the case study were obtained from a mesoscale numerical model calibrated with the adequate physical parameterizations for the region under study. The data used to feed the DLR analysis tool (wind speed and direction, temperature and radiation) covers $12 \mathrm{hr}$ and were extracted to $20 \mathrm{~m}$ above ground level (a.g.l.) for the lines' locations [13]. The spatial resolution of the data is $5 \mathrm{~km} x 5 \mathrm{~km}$. The predetermined meteorological conditions used by the TSO (fixed winter rating using a wind speed of $0.6 \mathrm{~m} / \mathrm{s}$, an ambient temperature of $15^{\circ} \mathrm{C}$ and a radiation of 1000 $\mathrm{W} / \mathrm{m}^{2}$ [5]) were also applied to determine the lines capacity limitation. The use of the TSO's conservative values give results that are within $99.8 \%$ of the values reported at [11]. According to [4], the common values 
used by TSOs varies between $0.5-0.61 \mathrm{~m} / \mathrm{s}$ for wind speed (direction not accounted for), $1000-1150 \mathrm{~W} / \mathrm{m}^{2}$ for solar irradiance, and temperature usually is adjusted seasonally (Portugal case) according to the highest temperature expected for the region.

To obtain the wind power generation, the wind speed data for $80 \mathrm{~m}$ a.g.l. were extracted from the mesoscale for each wind park. Then, based on the number of wind turbines of each park and the manufacturer guaranteed power curve, the wind power for each hour was computed.

\section{B. Methodology}

To ease the access to the data required by the DLR analysis, the tool was developed using georeferenced data for the power grid layout and meteorological data in a Geographic Information System (GIS) interface, the ArcGIS $®$, Fig. 2.

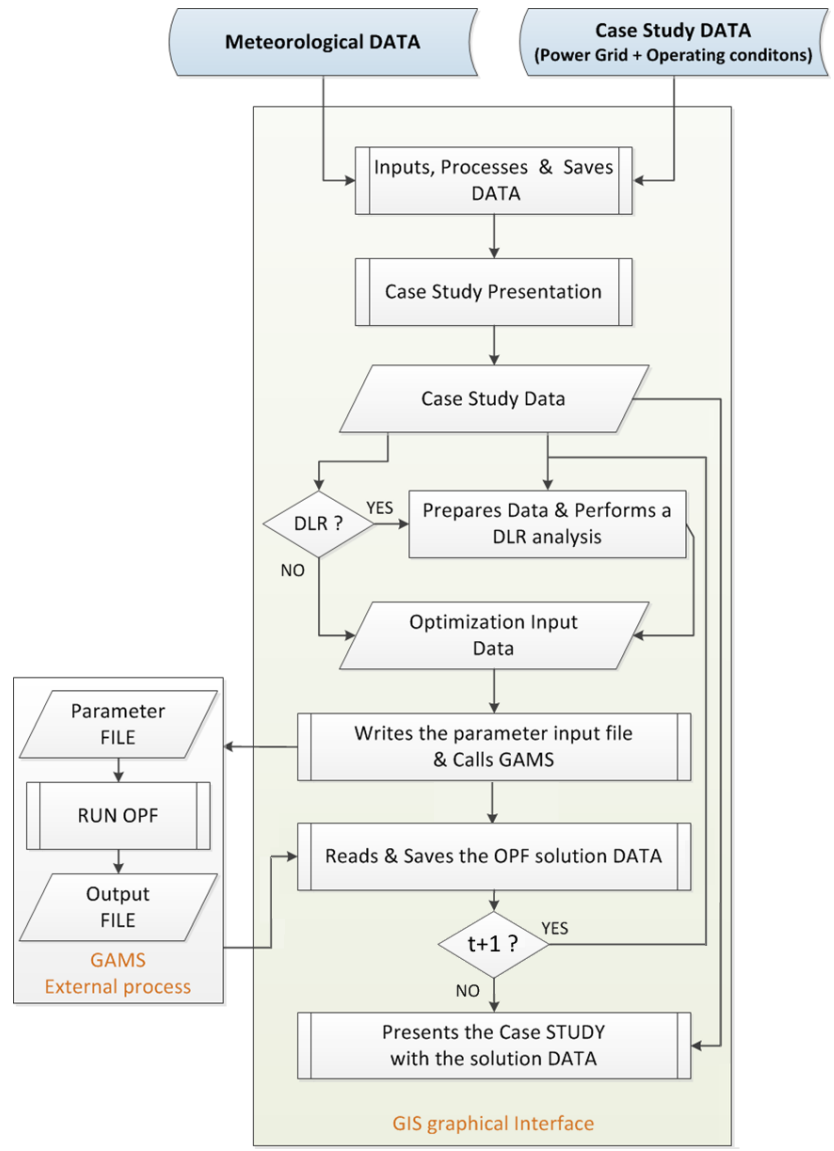

Fig. 2 Schematic representation of the DLR analysis tool.

The tool uses a numerical mesh of $5 \times 5 \mathrm{~km}$ cells (same resolution as the meteorological data) to divide the network into sections, narrowing the length of the lines segments that might be closer to congestion, i.e., the critical section. Each line segment experiences the meteorological conditions defined for its cell domain for an hourly time-period, over a horizon of 12 hours.

The direction of the conductor is assumed to be represented by a straight line segment, in the considered cell, and is computed from the coordinates of the line's input and output points (Fig. 3).

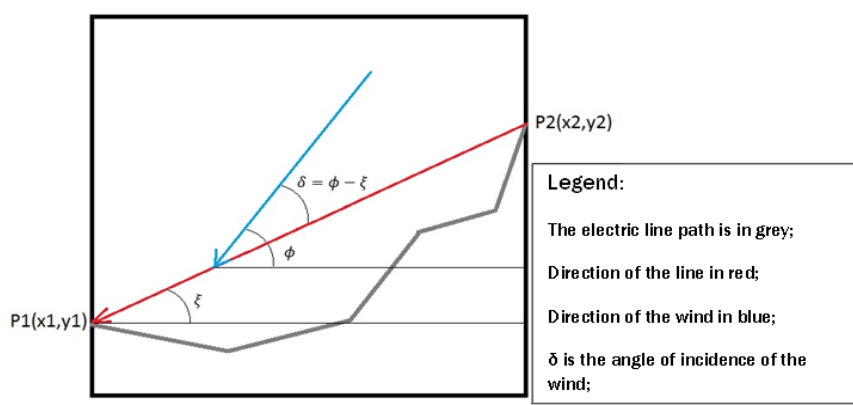

Fig. 3 Illustration of how to obtain the angle of incidence of the wind in the conductor.

The angle of incidence of the wind on the conductor is determined by the difference between the angles that the wind and the conductor present relative to the cell's horizontal line.

To operationally use the DLR analysis, an external tool referred as Optimized Power-flow Model (OPF) [14] was used to determine the power flow in the grid under analysis. The OPF model leads to a Non Linear Problem (NLP) that is initialized by the results of a simplified Linear Problem usually known as the direct current model. The mathematical model was implemented in GAMS® (General Algebraic Modelling System) and tested with several examples by comparing its results with the ones given by a commercial platform, PSSE $\AA$, with differences lesser than $1 \%$ [14].

The ArcGIS ${ }^{\circledR}$ interface reads the OPF output files (Excel) and internally saves the corresponding data for graphical presentation. The DLR analysis tool is capable to read the ArcGIS ${ }^{\circledR}$ data and save the OPF's parameterization, data usable in the iterative process (see Fig. 2)

\section{3) Results}

\section{A) DLR analysis tool applied to potentially congested lines}

To evaluate the advantages of using a DLR analysis, two scenarios were used, Table II, with weather conditions from the 23rd (1:00 p.m.) to the 24th (00:00 a.m.) of December 2009. This period was chosen for having high wind speeds that unleashes the occurrence of severe variations on wind power production (also known as wind power ramp events [15]), Fig. 4. During this period, the values of radiation are quite low, while the temperature keeps stable showing reduced variations.

Table II. Summarization of the study scenarios.

\begin{tabular}{|c|c|}
\hline Scenario & Designation \\
\hline A & $\begin{array}{c}\text { Optimization of the case study's electric grid } \\
\text { without DLR analysis (Baseline scenario). }\end{array}$ \\
\hline B & $\begin{array}{c}\text { Optimization of the case study's electric grid with } \\
\text { DLR analysis }\end{array}$ \\
\hline
\end{tabular}




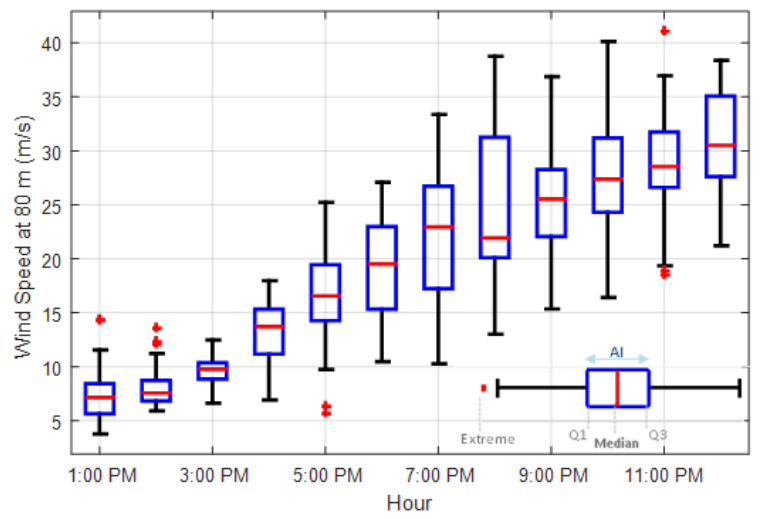

Fig. 4 Main characteristics of wind speed over the case study wind parks. The median is drawn in red and the edges of the box are the $25^{\text {th }}(\mathrm{Q} 1)$ and $75^{\text {th }}(\mathrm{Q} 3)$ percentiles. The whiskers extend

to 1.57 times the inter quartile range (AI) of the box edges.

Scenario A proposes to optimize the electrical network under study without applying the DLR analysis. In this case, the tool is fed with the TSO's capacity limits to determine the normal transmitted power. Scenario B is intended to allow a direct comparison of the line capacity factor obtained based on the ampacity values given by a DLR analysis with the ones obtained in scenario A. With this scenario, it is also possible to assess the influence of the DLR analysis on the congested lines. For this scenario, both, the CIGRE and Kuipers\&Brown models were applied in order to determine the additional line capacity obtained with the "real" meteorological conditions.

The aforementioned scenarios use the entire electrical network showed in Fig. 1 where the four power lines referenced by their code number, one $150 \mathrm{kV}$ and three $220 \mathrm{kV}$, were analyzed in detail for their importance in this case study. Results indicate saturation cases for the i) line 1089 between 4 p.m. and 9 p.m. and later at 00:00 a.m., and ii) lines 2170 and 2173 at 8:00 p.m. (Fig. 5, Fig. 6 and Table III). Line 2164 also came close to saturation at 8:00 p.m. It can be ascertained that the very fast increase on the wind speeds to values near or above $25 \mathrm{~m} / \mathrm{s}$ prompts many wind parks around Falagueira and Zezere buses to operate at nominal capacity (Fig. 4), causing the saturation of line 1089. Due to the wind speed intensification, at 7:00 p.m., some major wind parks such as Pinhal Interior (146 MW), Beiras (101 MW) and Alto Arganil (40 MW) are not operating due to cut-out wind speeds. At 8:00 p.m., the wind speeds slightly decrease (Fig. 4), allowing the wind parks previously mentioned to inject their maximum production capability into the grid and thus causing the saturation of lines 2170 and 2173 and nearly saturating the line 2164 ,

Table III. Wind conditions over the case scenario lines in the critical section.

\begin{tabular}{|c|c|c|c|c|c|}
\hline Line Code & & 1089 & 2164 & 2170 & 2173 \\
\hline TSO line capacity [MI & & 153 & 804 & 434 & 434 \\
\hline DLR line capacity [MVA] & \multirow{4}{*}{7 PM } & 256 & 1872 & 728 & 535 \\
\hline Increase line capacity [\%] & & $67 \%$ & $133 \%$ & $68 \%$ & $23 \%$ \\
\hline Wind Speed $[\mathrm{m} / \mathrm{s}]$ & & 8.2 & 9.1 & 8.6 & 4.1 \\
\hline Angle Direction $\left[{ }^{\circ}\right]$ & & 1 & 79 & 8 & 3 \\
\hline DLR line capacity [MVA] & \multirow{4}{*}{$8 \mathrm{PM}$} & 284 & 1766 & 762 & 674 \\
\hline Increase line capacity [\%] & & $86 \%$ & $120 \%$ & $76 \%$ & $55 \%$ \\
\hline Wind Speed $[\mathrm{m} / \mathrm{s}]$ & & 10.5 & 9.8 & 9.3 & 6.3 \\
\hline Angle Direction $\left[{ }^{\circ}\right]$ & & 2 & 43 & 10 & 12 \\
\hline
\end{tabular}

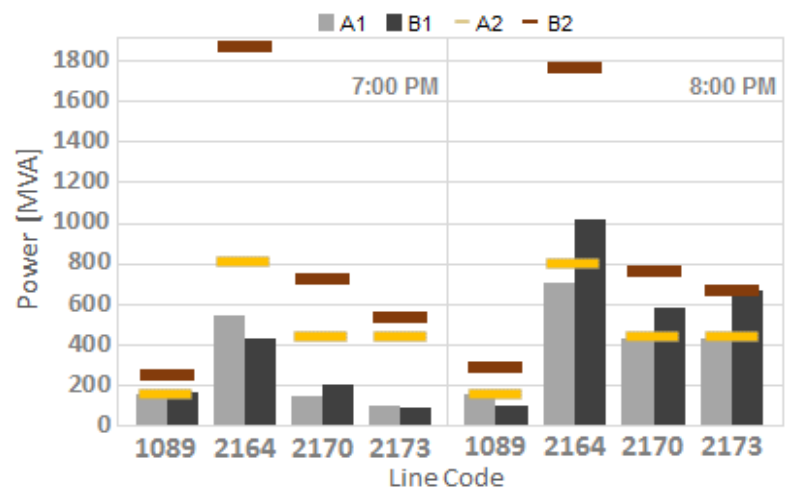

Fig. 5 Power transmitted (grey bars) and line capacity (colour lines) observed in each line: A1 - Power transmitted with standard grid conditions; B1 - Power transmitted with DLR grid conditions; A2 - Estimated line capacity using TSO conditions (Kuipers\&Brown Model); B2 - Estimated line capacity using DLR (CIGRE Model).

As expected, the DLR analysis reveals great increase on the line capacity limit values (Fig. 4). From scenario A, it can be ascertained that the critical lines are 1089, 2164, 2170 and 2173 , with the most critical period of time happening between 7:00 p.m. and 8:00 p.m.. With the exception of line 2173, DLR analysis tool shows that in fact that during the most critical hour (8:00 p.m.), the line close to saturation could still safely transport at least more $55 \%$ of power generation, Table III. This 55\% increase falls short compared to other lines for the same period and can be explained by the comparatively lower, wind speed $(6.3 \mathrm{~m} / \mathrm{s})$ allied with an unfavorable wind attack angle of $12^{\circ}$ in this particular section. Nevertheless, the wind speed considered is still much higher than the TSO current model consideration - 0.6 $\mathrm{m} / \mathrm{s}$. The results also show that there is a $96 \%$ overall improvement of the grid capacity for this case study, mitigating the risk of line saturation just to one line at 8:00 p.m., Fig. 6.
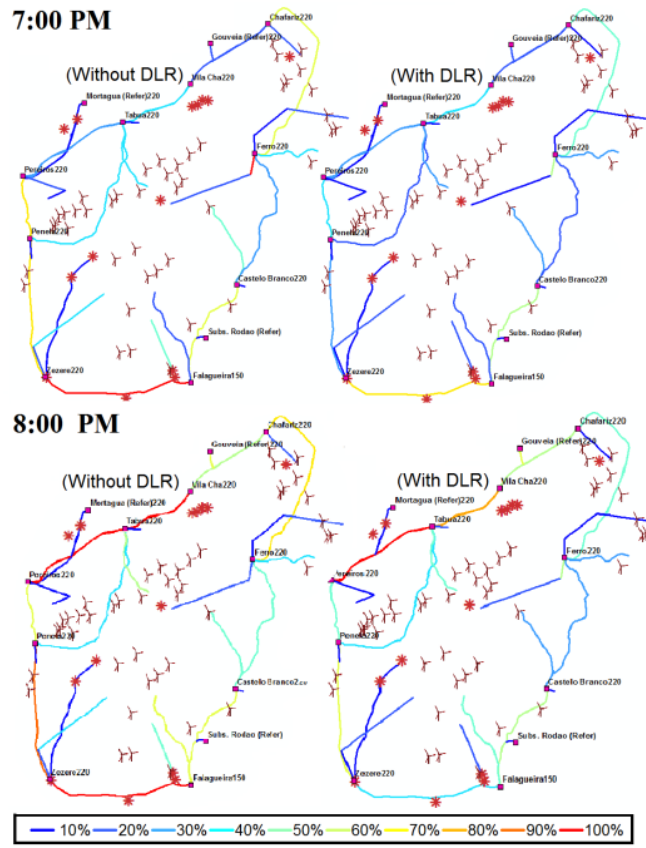

Fig. 6 Representation of the lines capacity factor increase without (scenario A) /with (scenario B) applying DLR analysis tool. 


\section{B) The impact of the weather conditions in line capacity}

To enhance further insights regarding the impact of the different meteorological conditions on the capacity increase, a statistical analysis of the results for all segment lines based on the correlation was performed, Table IV.

Table IV. Correlation between capacity increase and meteorological variables.

\begin{tabular}{|c|c|c|c|c|}
\hline $\begin{array}{c}\text { Capacity } \\
\text { Increase }\end{array}$ & Temperature & Irradiance & $\begin{array}{c}\text { Wind } \\
\text { speed }\end{array}$ & $\begin{array}{c}\text { Attack } \\
\text { Angle }\end{array}$ \\
\hline$\Delta(\mathrm{t})$ & 0.005 & -0.393 & 0.676 & 0.276 \\
\hline$\Delta(\mathrm{t}+1)-\Delta(\mathrm{t})$ & 0.057 & 0.007 & 0.644 & 0.602 \\
\hline
\end{tabular}

$\Delta(\mathrm{t})$ : Values absolute variation

$\Delta(\mathrm{t}+1)-\Delta(\mathrm{t})$ :Values relative difference variation.

As expected, both wind speed and attack angle have very strong correlations with the capacity increase having between them the greater impact on the cable thermal losses. The angle influence only becomes evident when is taken into consideration the relative variation over time (i.e., one-hour step-change - $\Delta(\mathrm{t}+1)-\Delta(\mathrm{t})$ ), that shows how sudden attack angle changes can significantly impact the line capacity. The impact of environment temperature in the thermal losses in the presence of strong winds is reduced, showing a very small positive correlation that can be attributed to the continuous increase behavior on both wind speed and temperature. Indeed, the environment temperature direct impact on power line capacity is expected to have a negative correlation. As expected, the irradiance shows a negative correlation with the line capacity increase.

The wind speed and angle of attack impact on the cables ampacity can be also seen in Fig. 7 .

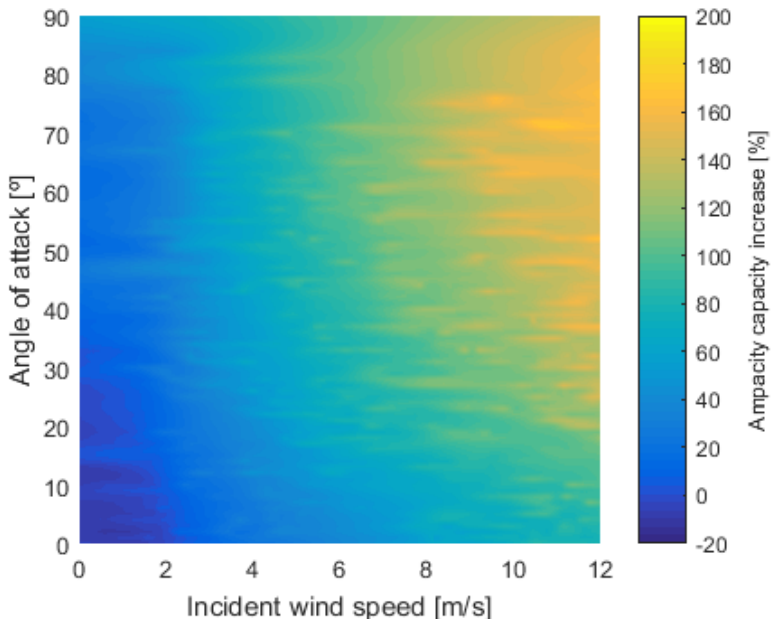

Fig. 7 Graphical analysis of capacity increase relative to the wind speed and direction.

From Fig. 7 is noticeable the intricacy relationship between the wind speed and angle of attack in the line ampacity capacity increase. Angles over $30^{\circ}$ have a more promptly effect in the increase of the power lines capacity. Overall, for wind speed above $6 \mathrm{~m} / \mathrm{s}$ it is possible to observe that angle of attack variations lead to higher ampacity increase while, for attack angles above $10^{\circ}$ the induced variations of wind speed prevail. For instance, as illustrated by the $8 \mathrm{~m} / \mathrm{s}$ wind speed values, the ampacity results for, $10^{\circ}, 20^{\circ}$ and $50^{\circ}$ attack angle values are $72 \%, 85 \%$ and $120 \%$, respectively. Fig. 7 also depicts that there are cases when the line capacity is actually lower than the capacity predicted by the TSO current model standards. As expected, this situation occurs for wind speed below 1 $\mathrm{m} / \mathrm{s}$ with an angle of attack lower than $10^{\circ}$.

\section{C) Critical sectors identification}

Since real life solutions to obtain the detailed meteorological information needed to assess the thermal balance analysis are very expensive, the DLR analysis tool can identify the critical line segment locations that impose the line's capacity limit, Fig. 8.

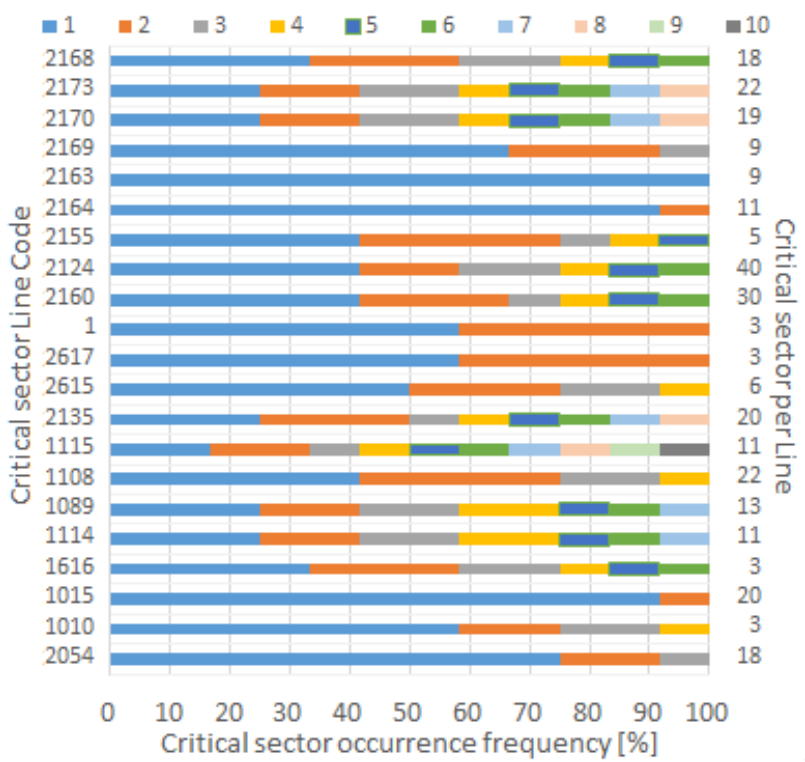

Fig. 8 Critical section occurrence rate for a 12-hour period. The colour bars represent the occurrence frequency of the most common occurring critical sectors in a decreasing order.

The critical sector analysis in Fig. 8 shows that among the 21 lines, some of them such as $2169,2163,2124$, 2160,1616 and 2054 have critical sectors that clearly are more prone to impose the critical capacity and thus limiting the power capacity in the whole line. For instance, line 2163 shows that in nine sectors, the critical one remains the same for the twelve hours analyzed. On the other hand, line 1115 presents a strong variation in its critical sector. For this line, ten different critical sectors were identified. The previous information can be very important to envisage the installation of monitoring stations along the lines, towards a heuristic approach rather than an equidistant ad hoc one, allowing a better choice for locating them on the power line, preferably on critical sectors with higher occurrence frequency. According to [7], this kind of heuristic approach can enable a proper monitoring system of the overhead power lines at reduced costs. 


\section{4) Final Remarks}

In this work, an operational tool for the dynamic line rating (DLR) analysis of overhead electric power lines is presented. A real case study, with high levels of wind power production, was developed to test the tool. The tool successfully replicated the "Steady-State" values from Portuguese TSO analysis. The applicability of the tool during a congestion scenario was also verified.

The results show the importance of assessing the cable's dynamical thermal balance, where the conductor's temperature for each section varies according to the local meteorological conditions. Complementarily, the results confirmed the importance of the speed and direction of the wind blowing over the cables. Thus, detailing the meteorological conditions assumes great importance in identifying the lines, which might be approaching critical states and thus in need of monitoring.

Since real life solutions to obtain those meteorological real time observations are very expensive and DLR proved to be able to suggest the location that imposes the line's capacity limit, it may be used on problematic lines to identify the most adequate location to install a meteorological station. Given proper local meteorological conditions, the DLR analysis evaluates when it is safe to inject more power into the power system, without requiring grid reinforcement or power curtailment.

As future development, it is envisaged to increase forecast capabilities up to 36 hours, to help prevent market-splitting occurrences in the day-ahead market within the Iberian electric market (MIBEL). Moreover, future developments will be done to account for the dynamic temperature computations, where the cable's thermal inertia will be used in the mathematical model.

\section{Acknowledgement}

This work was partly supported by the Integrated Research Programme on Wind Energy (IRPWIND), Grant agreement number: 609795.

\section{References}

[1] A. Michiorri, H.-M. Nguyen, S. Alessandrini, J. B. Bremnes, S. Dierer, E. Ferrero, B.-E. Nygaard, P. Pinson, N. Thomaidis, and S. Uski, "Forecasting for dynamic line rating," Renew. Sustain. Energy Rev., vol. 52, pp. 1713-1730, Dec. 2015.

[2] E. Fernandez, I. Albizu, M. T. Bedialauneta, A. J. Mazon, and P. T. Leite, "Review of dynamic line rating systems for wind power integration," Renew. Sustain. Energy Rev., vol. 53, pp. 80-92, Jan. 2016.

[3] D. Committee, I. Power, and E. Society, IEEE Standard for Calculating the Current-Temperature Relationship of Bare Overhead Conductors. 2013.

[4] J. Iglesias, G. Watt, D. Douglass, V. Morgan, R. Stephen, M. Bertinat, D. Muftic, R. Puffer, D. Guery, S. Ueda, K. Bakic, S. Hoffmann, T. Seppa, F. Jakl, C. Do Nascimento, F. Zanellato, and H.-M. Nguyen, Guide for thermal rating calculations of overhead lines, no. December. Paris: CIGRE, 2014.

[5] Ministry of Economy/Portuguese Republic, "Portaria n. ${ }^{0}$ 596/2010 de," Diário da República, vol. 147, 2010.
[6] T. Ringelband, M. Lange, M. Dietrich, and H.-J. Haubrich, "Potential of improved wind integration by dynamic thermal rating of overhead lines," in 2009 IEEE Bucharest PowerTech, 2009, pp. 1-5.

[7] M. Matus, D. Saez, M. Favley, C. Suazo-Martinez, J. Moya, G. Jimenez-Estevez, R. Palma-Behnke, G. Olguin, and P. Jorquera, "Identification of Critical Spans for Monitoring Systems in Dynamic Thermal Rating," IEEE Trans. Power Deliv., vol. 27, no. 2, pp. 1002-1009, Apr. 2012.

[8] T. O. Seppa, "Increasing transmission capacity by real time monitoring," in 2002 IEEE Power Engineering Society Winter Meeting. Conference Proceedings (Cat. No.02CH37309), 2002, vol. 2, pp. 1208-1211.

[9] A. Arroyo, P. Castro, R. Martinez, M. Manana, A. Madrazo, R. Lecuna, and A. Gonzalez, "Comparison between IEEE and CIGRE thermal behaviour standards and measured temperature on a $132-\mathrm{kV}$ overhead power line," Energies, vol. 8, no. 12, pp. 13660-13671, 2015.

[10] S. A. Trefilados de navarra, Overhead conductors. 2016.

[11] REN, "Caracterização da RNT para efeitos de acesso à rede.," 2017.

[12] General Cable, "Catálogos de Produtos,” 2014, pp. 49188.

[13] A. Couto, P. Costa, L. Rodrigues, V. V. Lopes, and A. Estanqueiro, "Impact of Weather Regimes on the Wind Power Ramp Forecast in Portugal," IEEE Trans. Sustain. Energy, vol. 6, no. 3, pp. 934-942, 2015.

[14] A. Castanho, "Análise de Sensibilidade da Capacidade de Transporte da Rede Elétrica ao Aumento da Produção Renovável Distribuída: Desenvolvimento de Modelos de Otimização [Reference in Portuguese]," University of Lisbon, 2017.

[15] M. Lacerda, A. Couto, and A. Estanqueiro, "Wind Power Ramps Driven by Windstorms and Cyclones," Energies, vol. 10, no. 10, p. 1475, Sep. 2017. 